\title{
A DESCRIPTION OF OPEN TOP CHAMBER SYSTEM FOR OIL PALM CARBON DIOXIDE ENRICHMENT
}

\author{
AMANINA, N S*; KHO, L K*; LINATOC, A C**; A'FIFAH, A R* and HANIFF, M H*
}

\begin{abstract}
Open Top Chamber (OTC) is one of the techniques to study plant responses to elevated carbon dioxide $\left(\mathrm{CO}_{2}\right)$ concentrations. A study on the effects of $\mathrm{CO}_{2}$ enrichment on oil palm growth, physiology and yield using OTC method was conducted at the Malaysian Palm Oil Board (MPOB) Research Station in Kluang, Johor, Malaysia. Oil palm clones P164 were cultivated in four OTC each with $9 \mathrm{~m}$ diameter and $10 \mathrm{~m}$ high. The OTC consists of a concrete structure with transparent multi-wall sheets. It has a truncated top for air aversion and to prevent $\mathrm{CO}_{2}$ dilution within the chamber by outside air. The $\mathrm{CO}_{2}$ gas was injected from nozzles mounted on the inner wall. The OTC was able to maintain a higher $\mathrm{CO}_{2}$ level inside the OTC than ambient level. Air temperature inside the OTC was slightly higher than ambient, while relative humidity and photosynthetically active radiation (PAR) inside the OTC were both slightly lower than ambient. A comparison of parameters measured inside the OTC and ambient provides a measure of the chamber effects. However, it could have either positive or negative effect on plant growth. The OTC method has some limitations and is only suitable for studying individual plant physiological responses to elevated $\mathrm{CO}_{2}$.
\end{abstract}

Keywords: Open Top Chamber, carbon dioxide enrichment, oil palm physiology, oil palm growth.

Date received: 22 July 2018; Sent for revision: 26 July 2018; Received in final form: 5 November 2018; Accepted: 10 April 2019.

\section{INTRODUCTION}

Carbon dioxide $\left(\mathrm{CO}_{2}\right)$ is the primary greenhouse gas that has been increasing in the atmosphere through human activities since the industrial revolution era. The contributors are burning fossil fuel (oil, coal and natural gas) for energy in machinery and transportation, open burning as well as deforestation (McCracken, 2008). In general, $\mathrm{CO}_{2}$ occurs naturally as part of the carbon cycle among the atmosphere, oceans, soil, plants and animals (EPA, 2017). Human activities put in more $\mathrm{CO}_{2}$ to

\footnotetext{
* Malaysian Palm Oil Board,

6 Persiaran Institusi, Bandar Baru Bangi,

43000, Kajang, Selangor, Malaysia.

E-mail: nuramanina@mpob.gov.my

** Faculty of Applied Science and Technology, Universiti Tun Hussein Onn Malaysia,Pagoh Campus, Km 1 Jalan Panchor, 84600 Muar, Johor, Malaysia.
}

the atmosphere and influence the forest as a natural sink and have modified the natural carbon cycle process (Pidwirny, 2006).

Increases in atmospheric $\mathrm{CO}_{2}$ and other infraredabsorbing greenhouse gasses contribute to a warmer climate in which surface air temperature rises to $1.5^{\circ} \mathrm{C}$ to $5.5^{\circ} \mathrm{C}$ (Adams et al., 1990). An increase in global temperatures can cause other changes, including rainfall patterns (Baker and Allen, 1994), melting snow or ice, rising sea level and increasing sea acidity (Barnett $e$ t al., 2005). Since 1970 to 2004, $\mathrm{CO}_{2}$ annual emission increased by about $80 \%$ and the projection to continue to increase as much as 500 to $1000 \mathrm{ppm}$ by the year 2100 (IPCC, 2007).

Rising $\mathrm{CO}_{2}$ levels markedly affect plant growth, physiology, and chemistry (Ziska, 2008). In plant metabolism, $\mathrm{CO}_{2}$ breaks down into smaller carbon molecules chemically. The products are used in chemical energy and to build plant structure. 
Photosynthesis process assimilates $\mathrm{CO}_{2}$ and turns it into organic molecules that produce about $96 \%$ of the total dry mass of a plant (Marschner, 1995). The main components of photosynthesis process are $\mathrm{CO}_{2}$, water and light energy, thus increasing $\mathrm{CO}_{2}$ availability which may affect plant growth and photosynthesis.

The $\mathrm{CO}_{2}$ fertilising effect of elevated $\mathrm{CO}_{2}$ may give impact to crop productivity and agroecosystems. Under higher $\mathrm{CO}_{2}$ concentration, the photosynthetic pathway plays an important role that influence plant growth and yield. Different plant species show a different response to elevated $\mathrm{CO}_{2}$ levels. Plants with $\mathrm{C}_{3}$ photosynthesis will respond markedly to increasing $\mathrm{CO}_{2}$ concentrations. Plants with $\mathrm{C}_{4}$ photosynthesis will show little response to rising atmospheric $\mathrm{CO}_{2}$ because they have a mechanism to increase the concentration of $\mathrm{CO}_{2}$ in leaves that causes $\mathrm{CO}_{2}$ saturation of photosynthesis at current ambient concentrations (Allen and Prasad, 2004).

Being a $\mathrm{C}_{3}$ plant, oil palm growth and yield are expected to be improved under high $\mathrm{CO}_{2}$ levels through increased photosynthetic rates, reduced photorespiration, and increased water use efficiency. The previous experiment on oil palm seedlings had shown that $\mathrm{CO}_{2}$ at $800 \mathrm{ppm}$ increased the seedling biomass by about twice of control (Ibrahim et al., 2010). However, the increasing temperature, poor soil nutrient, and inadequate water supply could limit the advantage of high $\mathrm{CO}_{2}$ on oil palm growth, fresh fruit bunch production or oil quality. Therefore, increasing amount of $\mathrm{CO}_{2}$ levels could have both detrimental and beneficial effects on oil palm crop.

Open Top Chamber (OTC) is a method used to study the effects of elevated $\mathrm{CO}_{2}$ and other atmospheric gases on vegetation. It is a plastic enclosure, with an open top, constructed of metal frame covered by panels of polyvinyl chloride plastic film (Machacova, 2010). A truncated top or frustum averts air and prevents $\mathrm{CO}_{2}$ dilution within the chamber by outside air. Air is pulled into the bottom of the chamber, enriched with $\mathrm{CO}_{2}$, and then blown through the open top of the chamber (Figure 1).

\section{OPEN TOP CHAMBER STRUCTURE}

The OTC facility for $\mathrm{CO}_{2}$ enrichment on oil palm is located at the Malaysian Palm Oil Board (MPOB) Research Station in Kluang, Johor, Malaysia. The OTC dimension is $9 \mathrm{~m}$ diameter and $10 \mathrm{~m}$ high, suitable for growing a single oil palm until maturity (Figure 2). The OTC consists of a concrete structure with aluminum frames to hold the $6 \mathrm{~mm}$ thick transparent multi-wall polycarbonate sheet with a direct solar transmission of $76 \%$ (Sabic Innovative Plastics, USA). It has a truncated top for air aversion

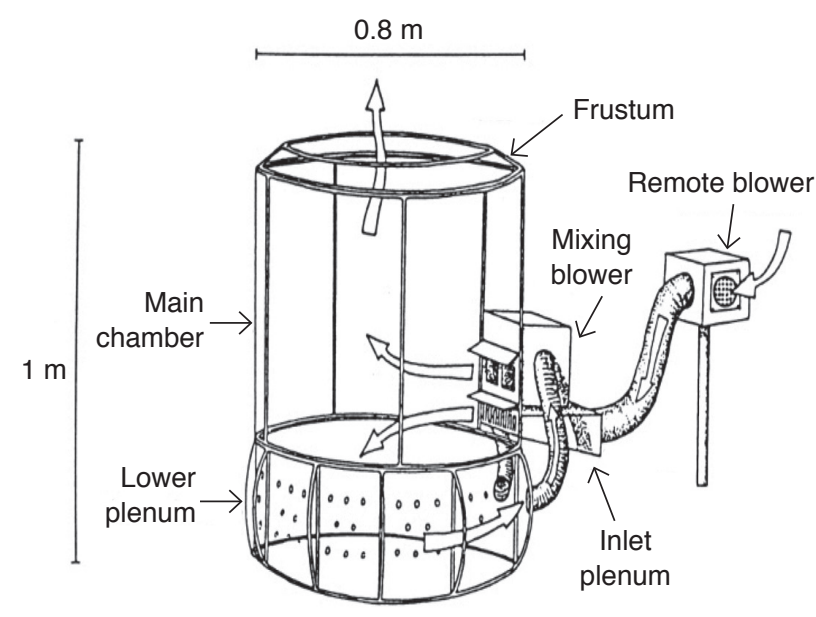

Figure 1. An Open Top Chamber design for salt marsh vegetation by Drake et al. (1989).

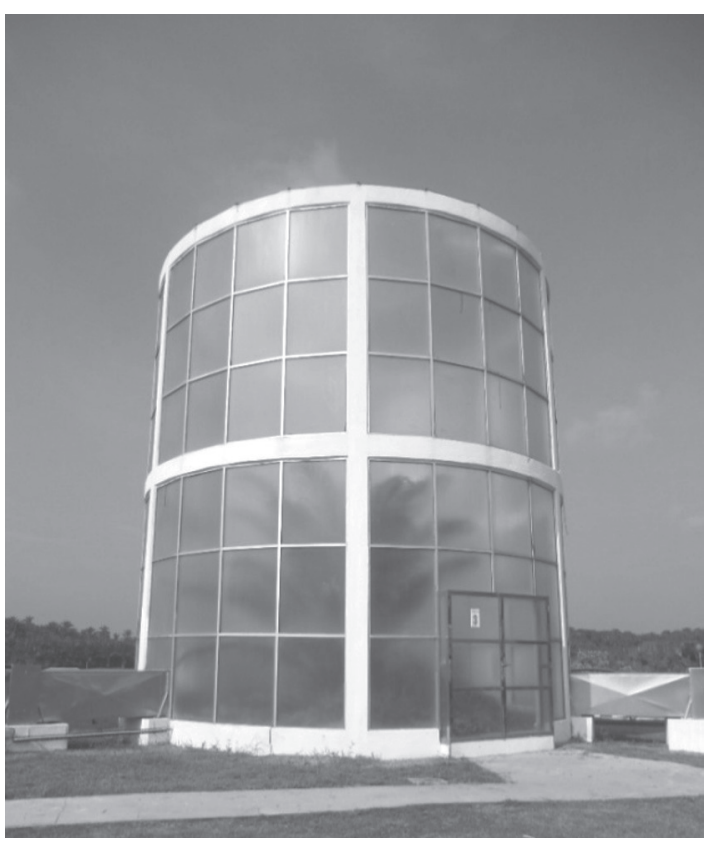

Figure 2. An Open Top Chamber (10 $m$ high $x 9 \mathrm{~m}$ diameter) at MPOB Kluang Station, Johor, Malaysia.

and to prevent $\mathrm{CO}_{2}$ dilution within the chamber by outside air. Three blower fans $(76 \mathrm{~cm} \times 76 \mathrm{~cm})$ are located at the basal part of the OTC and work as $\mathrm{CO}_{2}$ mixers. The $\mathrm{CO}_{2}$ gas was injected from nozzles mounted on the inner wall and blower fans then circulated the $\mathrm{CO}_{2}$ inside the OTC at low speed (Figure 3). The blower fans distribute the high $\mathrm{CO}_{2}$ concentration and maintain inside air temperature evenly throughout the oil palm canopy. Each OTC is equipped with a gas regulator and a flow meter.

\section{CARBON DIOXIDE CONTROL SYSTEM}

Liquid $\mathrm{CO}_{2}$ was transferred through a vaporiser, a regulator and finally distributed inside the OTC (Figure 4). Vaporised $\mathrm{CO}_{2}$ was distributed evenly 


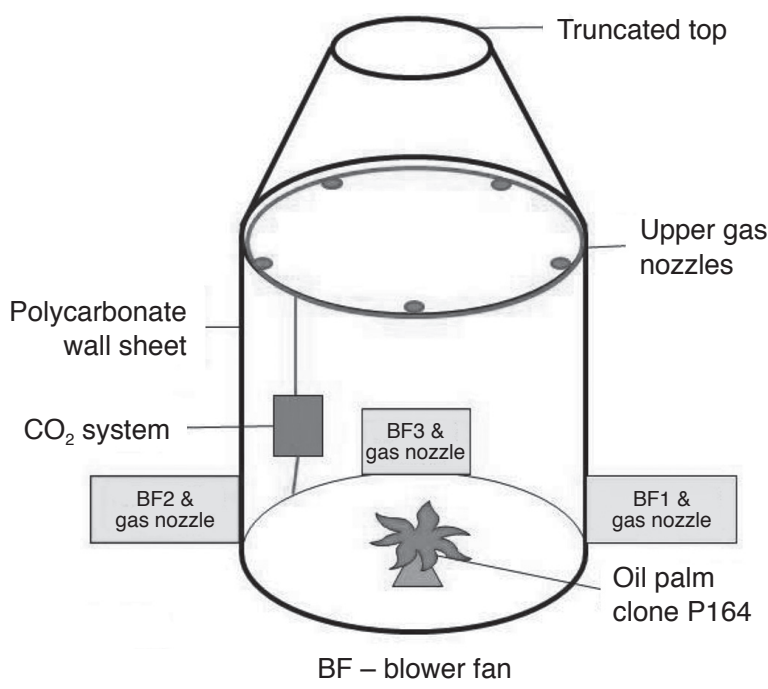

Figure 3. Open Top Chamber diagram with three blower fans, a truncated top and carbon dioxide system.

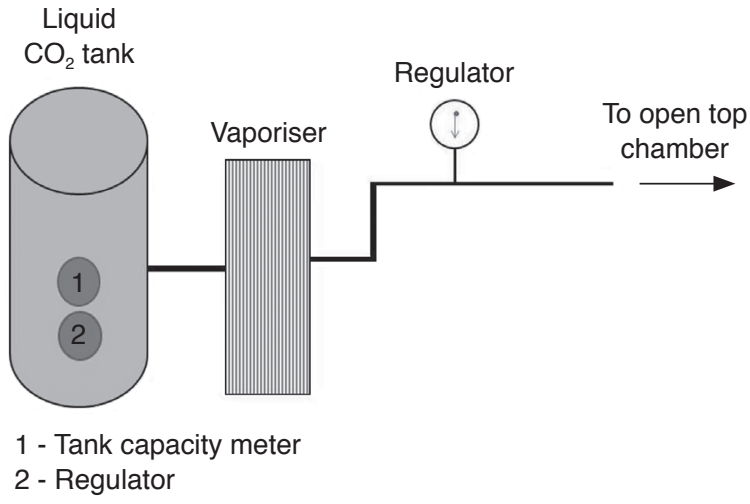

Figure 4. Liquid carbon dioxide goes through a vaporiser and a regulator before being distributed to four units of Open Top Chambers.

via four channels in each chamber i.e, Blower Fan 1, Blower Fan 2, Blower Fan 3 and upper gas nozzles through flow meters (Figure 5). The $\mathrm{CO}_{2}$ at $99.8 \%$ purity was injected through a pressure regulator into the chambers at 10 litres min $^{-1}$ during active photosynthesis period (8.00 to $11.00 \mathrm{am}$ ). During enrichment, three units of blower fan ran at low speed $\left(<0.5 \mathrm{~m} \mathrm{~s}^{-1}\right)$ to disperse $\mathrm{CO}_{2}$ evenly throughout the chamber. This is to ensure that the leaf boundary layer is removed and to increase $\mathrm{CO}_{2}$ diffusion into the leaf mesophyll (Aldrich and Bartok, 1994).

\section{ASSESSMENT OF ENVIRONMENTAL CONDITIONS WITHIN OPEN TOP CHAMBER}

The $\mathrm{CO}_{2}$ level within all OTC was monitored by a $\mathrm{CO}_{2}$ gas analyser (LI-820, LICOR, USA) which directly analyse air sampled by a micropump unit. Photosynthetically active radiation (PAR) was measured using a quantum sensor (LI-190, LICOR, USA). This data is important to determine

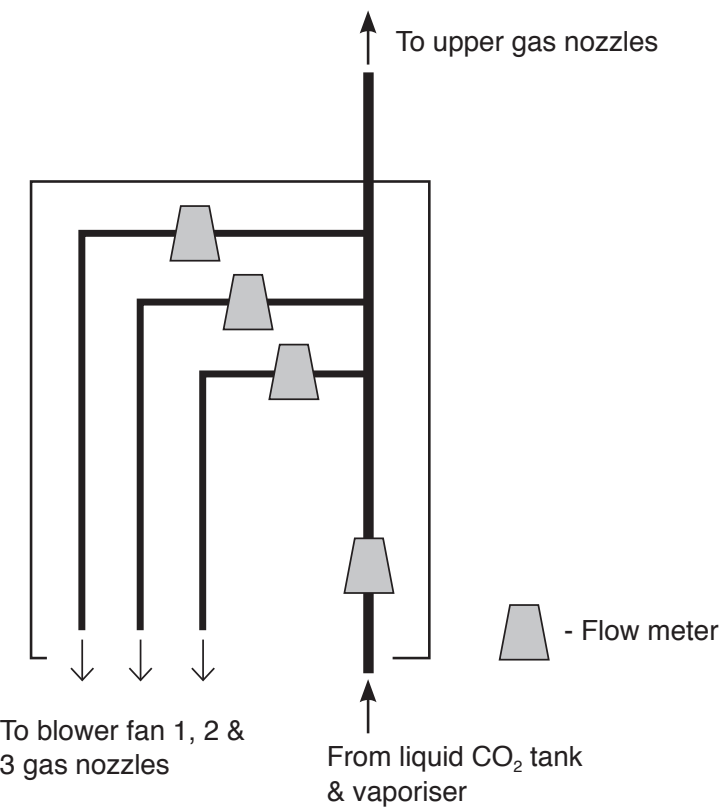

Figure 5. Vaporised carbon dioxide gas flow to upper gas nozzles and three units of blower fan gas nozzles in each Open Top Chamber.

the difference in incoming light within OTC and outside ambient light condition (Messerli et al., 2015). Air temperature, relative humidity and PAR were continuously measured at oil palm canopy height (Campbell Scientific, 1982) in each OTC. The sensor height can be adjusted manually as the palm grows taller and to avoid shading effects from the OTC concrete structure. All installed sensors $\left(\mathrm{CO}_{2^{\prime}}\right.$ temperature, relative humidity and PAR) were mounted on a pole with an adjustable arm. Data were recorded at $1 \mathrm{hr}$ intervals and can be retrieved from the control system, i.e. Supervisory Control and Data Acquisition (SCADA).

Results show that the OTC was able to maintain a higher $\mathrm{CO}_{2}$ level inside the OTC during daytime (Figure 6a). The $\mathrm{CO}_{2}$ concentration was measured at a central location near the oil palm canopy. Air temperature inside the OTC was slightly higher up to $5 \%$ (Figure $6 b$ ), relative humidity was slightly lower and PAR diminished by as much as $40 \%$ (Figures $6 c$ and $6 d$ ). It is clear that OTC alters microenvironment compared to unchambered plots particularly temperature, light intensity, relative humidity and wind velocity (Paul and Bert, 1993).

\section{CONCLUSION}

A comparison of parameters measured inside the OTC and ambient provides a measure of the chamber effects. However, the effects could have either positive or negative effects on plant growth. For instance, shading effect by the OTC wall could limit light intensity. The increase in air temperature inside the OTC could cause plant water deficits. 

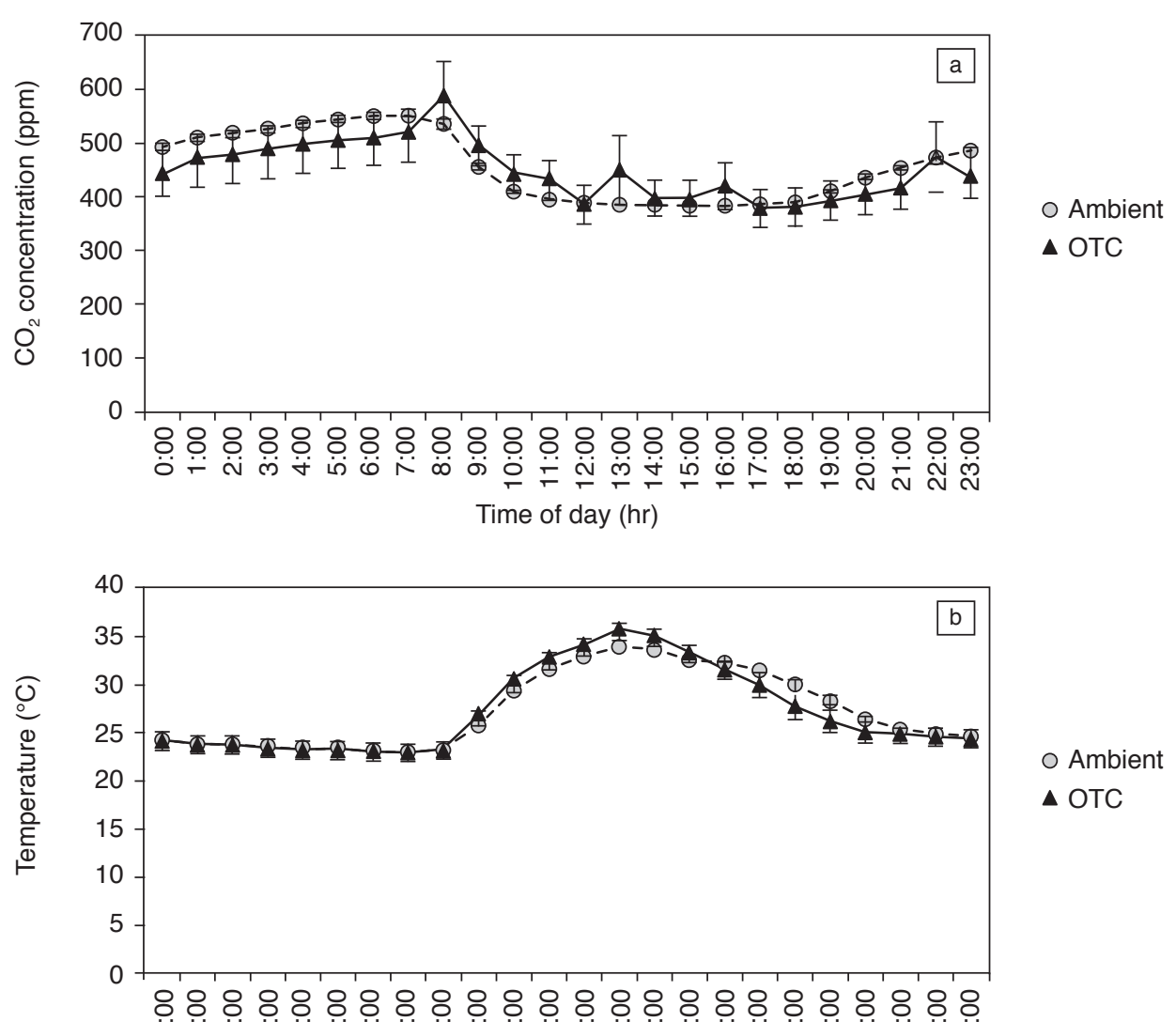

O Ambient

$\triangle$ OTC

Time of day (hr)

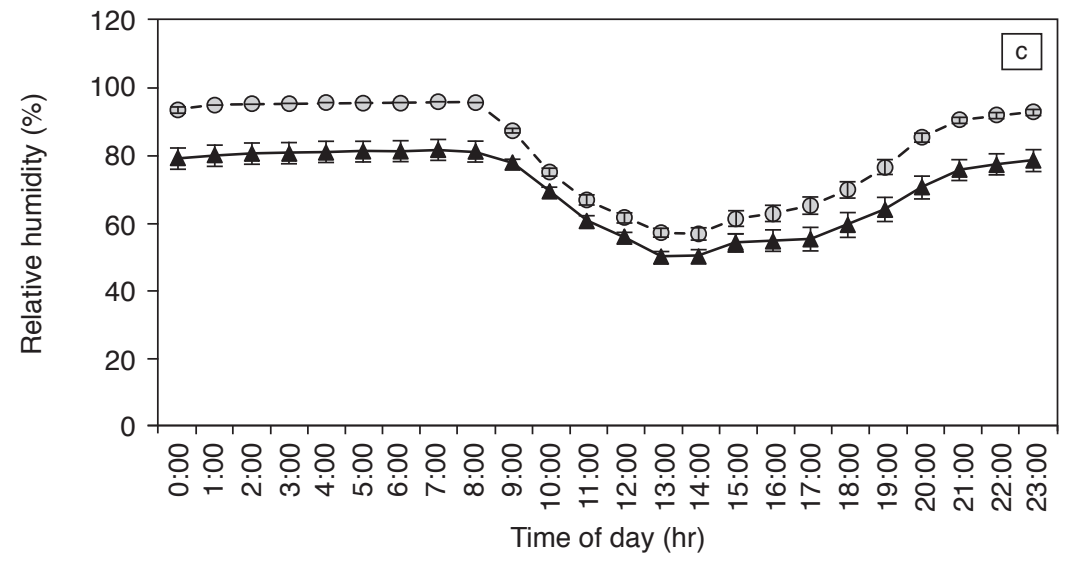

O Ambient

$\triangle$ OTC

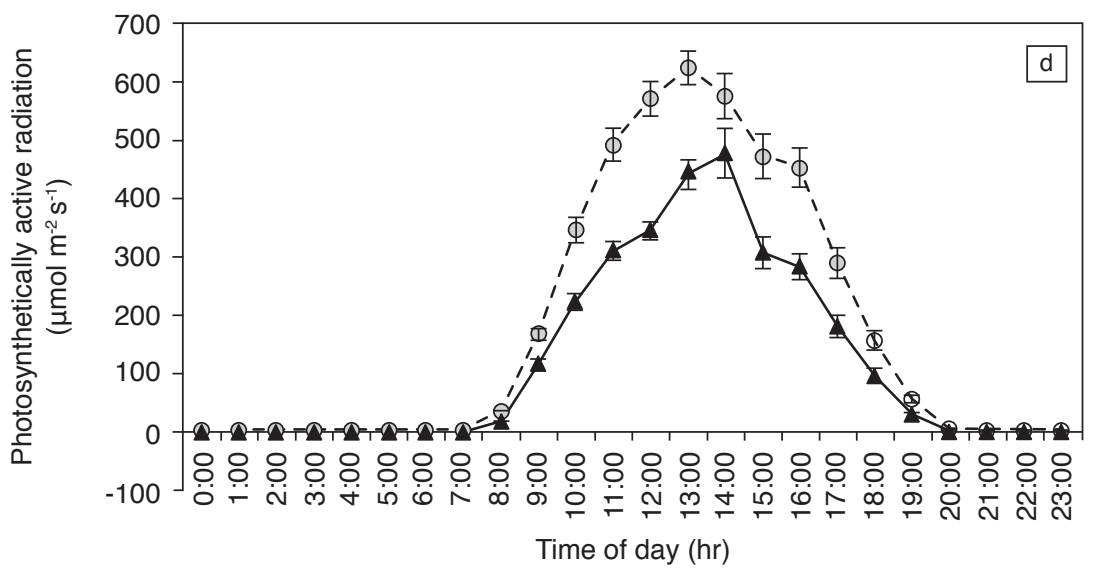

O Ambient

$\triangle \mathrm{OTC}$

Figure 6. Diurnal pattern of (a) carbon dioxide concentration, (b) air temperature, (c) relative humidity and (d) photosynthetically active radiation inside the Open Top Chamber (OTC) and ambient. Each point represents an average of four weeks data on daily basis $(n=744)$. Error bar represents standard error of mean. 
The OTC method has some limitations and is only appropriate for studying individual plant physiological responses to elevated $\mathrm{CO}_{2}$. Further investigation is required to explore its suitability for oil palm.

\section{ACKNOWLEDGEMENT}

The authors would like to thank the DirectorGeneral of MPOB for permission to publish this article and the staff of Crop Physiology, Biology Division, MPOB for their assistance.

\section{REFERENCES}

Adams, R M; Rosenzweig, C; Peart, R M; Ritchie, J T; Mccarl, B A; Glyer, J D; Curry, R B; Jones, J W; Boote, K J and Allen, L H Jr (1990). Global climate change and US agriculture. Nature, 345: 219-224.

Aldrich, R A and Bartok, J W (1994). Greenhouse engineering. Carbon Dioxide Enrichment (Sailus, M; Chris, $\mathrm{N}$ and Sanders, $\mathrm{M}$ eds.). University of Connecticut Publication, Ithaca, New York.

Allen, L H Jr and Prasad, P V V (2004). Crop responses to elevated carbon dioxide. Encyclopaedia of Plant and Crop Science. Marcel Dekker Inc., New York. p. 346-348.

Baker, J T and Allen, L H Jr (1994). Assessment on the impact of rising carbon dioxide and other potential climate changes on vegetation. Environmental Pollution, 83: 223-235.

Barnett, T P; Adam, J C and Lettenmaier, D P (2005). Potential impacts of warming climate on water availability in snow-dominated regions. Nature, 438: 303-309.

Campbell Scientific (1982). Campbell Scientific Instruction Manual for LI190SB Quantum Sensor Revision 2/15. Campbell Scientific Incorporated, Utah, USA.

Drake, B G; Leadley, P W; Arp, W J; Nassiry, D and Curtis, P S (1989). An open top chamber for field studies of elevated atmospheric $\mathrm{CO}_{2}$ concentration on salt marsh vegetation. Functional Ecology, 3(2): 363-371.
Environmental Protection Agency of the United States (EPA) (2017). Greenhouse gas emissions Overview of greenhouse gases. http://www.epa. gov.my / ghgemissions / overview-greenhousegases\# carbon-dioxide, accessed on 29 March 2017.

Ibrahim, M H; Jaafar, H Z E; Haniff, M H and Yusof, M R (2010). Changes in growth and photosynthesis pattern of oil palm (Elaeis guineensis Jacq.) seedlings exposed to short-term $\mathrm{CO}_{2}$ enrichment in a closed chamber. Acta Physiologiae Plantarum., 32: 305-313.

Intergovernmental Panel on Climate Change (IPCC) (2007). The physical science basis. Contribution of Working Group I to the Fourth Assessment Report of the Intergovernmental Panel on Climate Change. Cambridge University Press, Cambridge, UK. 976 pp.

Machova, K (2010). Open top chamber and free air $\mathrm{CO}_{2}$ enrichment - Approaches to investigate tree responses to elevated $\mathrm{CO}_{2}$. iForest - Biogeosciences and Forestry, 3: 102-105.

Marschner, H (1995). Mineral Nutrition of Higher Plants. Second edition. Academic Press, London, United Kingdom. 889 pp.

Mccracken, M C (2008). Prospects for future climate change and the reasons for early action. J. Air and Waste Management Association, 58: 735-786.

Messerli, J; Bertrand, A; Bourassa, J; Bèlanger, G; Castonguay, Y; Tremblay, G; Baron, V and Seguin, P (2015). Performance of low-cost open-top chambers to study long-term effects of carbon dioxide and climate under field conditions. Agronomy J., 107(3): 916-920.

Paul, W L and Bert, G D (1993). Open top chambers for exposing plant canopies to elevated $\mathrm{CO}_{2}$ concentration for measuring net gas exchange. Vegetatio, 104(3): 3-15.

Pidwirny, M (2006). The carbon cycle. Fundamental of Physical Geography. Second edition. University of British Columbia, Canada. 372 pp.

Ziska, LH (2008). Rising atmospheric carbon dioxide and plant biology: The overlooked paradigm. Controversies in Science and Technology, From Climate to Chromosomes (Kleinman, D L and Cloud-Hansen, K A eds.). New Rochele: Liebert Incorporated. p. 379-400. 